\title{
Evaluation of Streptococcus iniae killed bacterin and live attenuated vaccines in hybrid striped bass through injection and bath immersion
}

\author{
Jeffrey B. Locke ${ }^{1,2,6}$, Mike R. Vicknair ${ }^{3}$, Vaughn E. Ostland ${ }^{3}$, Victor Nizet $^{1,2,4}$, \\ John T. Buchanan ${ }^{1,5, *}$ \\ ${ }^{1}$ Department of Pediatrics, Division of Pharmacology and Drug Discovery, University of California, San Diego, \\ 9500 Gilman Drive, MC 0687, La Jolla, California 92093-0687, USA \\ ${ }^{2}$ Center for Marine Biotechnology and Biomedicine, Scripps Institution of Oceanography, University of California, \\ San Diego, 9500 Gilman Drive, MC 0208, La Jolla, California 92093-0208, USA \\ ${ }^{3}$ Kent BioEnergy, 11125 Flintkote Avenue, Suite J, San Diego, California 92121, USA \\ ${ }^{4}$ Skaggs School of Pharmacy and Pharmaceutical Sciences, University of California, San Diego, 9500 Gilman Drive, \\ MC 0657, La Jolla, California 92093-0657, USA \\ ${ }^{5}$ Aqua Bounty Technologies, 8395 Camino Santa Fe, San Diego, California 92121, USA \\ ${ }^{6}$ Present address: Trius Therapeutics, 6310 Nancy Ridge Drive, Suite 105, San Diego, California 92121, USA
}

\begin{abstract}
Streptococcus iniae poses a serious threat to finfish aquaculture operations worldwide. Stringent regulatory standards limit the use of antibiotics to treat $S$. iniae infections; improved vaccination strategies are thus of great interest. We investigated the potential for efficient, non-injectable batch vaccination via the use of live attenuated vaccines. Three attenuated $S$. iniae strains with genetic mutations eliminating the production of virulence factors - capsular polysaccharide $(\Delta c p s D)$, M-like protein $(\Delta \operatorname{sim} A)$, and phosphoglucomutase $(\Delta p g m A)$ - were evaluated in parallel with an adjuvanted, formalin-killed, whole-cell $S$. iniae bacterin. Juvenile hybrid striped bass (HSB; Morone chrysops $\times$ M. saxatilis) were vaccinated through intraperitoneal (i.p.) injection or bath immersion and held for 800 degree-days prior to challenge with a lethal dose of the virulent wild-type (WT) $S$. iniae parent strain. The $\Delta c p s D, \Delta p g m A$, and bacterin vaccines provided the highest level of vaccination safety ( $0 \%$ mortality), whereas the $\Delta \operatorname{sim} A$ mutant, although it caused 12 to $16 \%$ vaccinationrelated mortality, was the only vaccine candidate to provide $100 \%$ protection in both i.p. and immersion delivery models. Our studies demonstrate the efficacy of live attenuated vaccines for prevention of $S$. iniae infection, and identify immersion delivery of live vaccines as an attractive option for use in commercial aquaculture settings.
\end{abstract}

KEY WORDS: Streptococcus iniae $\cdot$ Live attenuated vaccine $\cdot$ Hybrid striped bass $\cdot$ M-like protein Capsular polysaccharide $\cdot$ Phosphoglucomutase

\section{INTRODUCTION}

Streptococcus iniae was first isolated from an Amazon freshwater dolphin Inia geoffrensis in the 1970s (Pier \& Madin 1976) and since then has been shown to cause infection in a wide variety of fresh and saltwater finfish. S. iniae outbreaks predominantly occur in intensive aquaculture operations and affect many commercially important fish species, including tilapia, salmon, trout, yellowtail, barramundi, flounder, and hybrid striped bass (HSB) (Agnew \& Barnes 2007). Common clinical signs of $S$. iniae infection include loss of orientation, lethargy, ulcers, and exophthalmia (Eldar et al. 1995). Mortality resulting from S. iniae 
infection is often attributed to meningoencephalitis (Eldar et al. 1995), and is responsible for annual losses exceeding USD 100 million in aquaculture (Shoemaker et al. 2001). Despite the prevalence of $S$. iniae as an aquatic pathogen, therapeutic options for treating or preventing infection are limited.

While vaccines have been a viable therapeutic strategy to prevent infections caused by many bacterial fish pathogens (Sommerset et al. 2005), attempts to develop Streptococcus iniae vaccines have been met with limited success in part due to a general lack of efficacy over extended time periods (Agnew \& Barnes 2007) and the re-emergence of serotypic variants (Bachrach et al. 2001). The predominant vaccination approach for $S$. iniae utilizes whole-cell, killed bacterins (Eldar et al. 1997, Klesius et al. 2000). There are currently 2 whole-cell killed commercial $S$. iniae vaccines, Norvax ${ }^{\circledR}$ Strep $S i$ and AquaVac ${ }^{\mathrm{TM}}$ Garvetil $^{\mathrm{TM}}$ (Intervet/Schering-Plough Animal Health), but neither is approved for use in the USA.

Transposon and targeted mutagenesis techniques have facilitated the development of live attenuated vaccines as an alternative vaccination strategy for Streptococcus iniae (Buchanan et al. 2005, Locke et al. 2008). The attractiveness of live attenuated vaccines relative to bacterin vaccines lies in their ability to stimulate a robust humoral and cell-mediated immune response, which can translate into long-term adaptive protection against subsequent exposure to a virulent wild-type (WT) strain (Marsden et al. 1996, 1998, Zlotkin et al. 2003). A key step towards targeted live attenuated vaccine development involves understanding $S$. iniae virulence factors. To date, only a handful of these determinants have been characterized for $S$. iniae in the context of fish virulence: phosphoglucomutase (Buchanan et al. 2005), capsular polysaccharide (Locke et al. 2007a, Lowe et al. 2007, Shutou et al. 2007), streptolysin S (Fuller et al. 2002, Locke et al. 2007b), and M-like protein (Baiano et al. 2008, Locke et al. 2008).

Mutation of any Streptococcus iniae virulence gene resulting in significant in vivo attenuation warrants consideration for preliminary testing of the mutant as a vaccine candidate. Previously, through intraperitoneal (i.p.) vaccination of HSB, we found protection levels of $100 \%$ against WT S. iniae (after 1400 degree-days) with an M-like protein mutant strain $(\Delta \operatorname{sim} A)$ (Locke et al. 2008) and 90 to $100 \%$ protection (after 2000 degreedays) with a phosphoglucomutase-deficient transposon mutant $(\Delta p g m A)(B u c h a n a n$ et al. 2005). Our allelic replacement of the $c p s D$ gene in the $S$. iniae capsular polysaccharide biosynthesis operon resulted in a highly attenuated mutant strain $(\Delta c p s D)$ (Locke et al. 2007a), and preliminary testing showed efficacy of this mutant at higher doses in a similar HSB i.p. vaccination model (data not shown). However, vaccination by immersion has a number of advantages over injectionbased approaches, including reduced handling and stress to fish, lower cost, avoidance of damage to fillets, and the potential to more effectively stimulate the teleost immune response by delivery through a route utilized by aquatic pathogens.

We explored the protective capacity of a formalinkilled Streptococcus iniae bacterin (WT K288) in parallel with 3 isogenic live attenuated mutant $S$. iniae strains $(\Delta c p s D, \Delta \operatorname{sim} A$, and $\Delta p g m A)$, which are deficient in capsular polysaccharide, M-like protein, and phosphoglucomutase, respectively. Each vaccine was evaluated in juvenile HSB in parallel through i.p. injection and bath immersion. Survival following a lethal challenge with WT $S$. iniae was used to assess vaccine efficacy after an 800 degree-day holding period. These studies are the first to evaluate immersion delivery of live attenuated $S$. iniae vaccines and to directly compare efficacy of multiple live $S$. iniae vaccine candidates to a killed bacterin.

\section{MATERIALS AND METHODS}

Bacterial strains, culture conditions, and DNA techniques. Streptococcus iniae WT strain K288 was isolated from the brain of a diseased HSB at the Kent SeaTech aquaculture facility in Mecca, CA (Buchanan et al. 2005). The $\Delta \operatorname{sim} A$ (Locke et al. 2008) and $\Delta c p s D$ (Locke et al. 2007a) allelic replacement mutants and the $\triangle p g m A$ transposon mutant (Buchanan et al. 2005) were all generated in the strain K288 background (Table 1). Mutant and WT S. iniae strains were cultured at $30^{\circ} \mathrm{C}$ in Todd-Hewitt broth (THB; Hardy Diagnostics) or on Todd-Hewitt agar plates (THA). Enumeration of colony-forming units (CFU) was performed by serially diluting bacteria in phosphate-buffered saline (PBS; pH 7.4) and plating on THA. A Colony FastScreen Kit (EPICENTRE Biotechnologies) was used to isolate genomic DNA for PCR identification of $S$. iniae colonies isolated from challenged fish. Vaccine strains were identified through amplification of regions spanning the allelic exchange or transposon insertion sites as previously described (Buchanan et al. 2005, Locke et al. 2007a, 2008).

Preparation of formalin-killed bacterin. WT K288 Streptococcus iniae was grown to early stationary phase (optical density at $600 \mathrm{~nm}\left[\mathrm{OD}_{600}\right] \approx 0.80$; Spectronic 20D spectrophotometer). CFU were enumerated through plating serial dilutions of the 0.80 culture prior to formalin inactivation via room temperature $(21 \pm$ $1^{\circ} \mathrm{C}$ ) incubation for $72 \mathrm{~h}$ with $0.07 \%$ formaldehyde (v/v). A $100 \mu \mathrm{l}$ aliquot of the culture was plated on THA and incubated for $48 \mathrm{~h}$ at $30^{\circ} \mathrm{C}$ to ensure total killing. 
Table 1. Streptococcus iniae vaccine strains and doses. CFU = colony-forming units, i.p. = intraperitoneal, WT = wild-type

\begin{tabular}{|c|c|c|c|c|}
\hline Strain & Description & $\begin{array}{l}\text { I.p. dose } \\
\text { (CFU) }\end{array}$ & $\begin{array}{l}\text { Immersion dose } \\
\left(\mathrm{CFU} \mathrm{ml} \mathrm{l}^{-1}\right)\end{array}$ & Reference \\
\hline K288 & Bacterin prepared from WT strain & $3 \times 10^{8}$ & $4 \times 10^{7}$ & Buchanan et al. (2005) \\
\hline$\Delta \operatorname{sim} A$ & M-like protein (SiM) allelic replacement mutant & $3 \times 10^{6}$ & $3 \times 10^{7}$ & Locke et al. (2008) \\
\hline$\Delta c p s D$ & Capsular polysaccharide allelic replacement mutant & $3 \times 10^{7}$ & $3 \times 10^{7}$ & Locke et al. (2007a) \\
\hline$\Delta p g m A$ & Phosphoglucomutase transposon insertion mutant & $3 \times 10^{7}$ & $3 \times 10^{7}$ & Buchanan et al. (2005) \\
\hline
\end{tabular}

Bacteria were centrifuged $(3250 \times g$ for $15 \mathrm{~min})$ and resuspended in supernatant to an $\mathrm{OD}_{600}$ of 5.0. EMULSIGEN $^{\circledR}$ oil-in-water adjuvant (MVP Laboratories) was added to a final concentration of $20 \%$ (v/v) with the bacterial solution. The bacterin was stored at $4{ }^{\circ} \mathrm{C}$ and used within $1 \mathrm{wk}$ of preparation.

Preparation of live vaccines. Glycerol aliquots of each Streptococcus iniae strain were used to start static $3 \mathrm{ml}$ overnight cultures $(\sim 16 \mathrm{~h})$ which were then diluted 1:10 in fresh THB and grown to mid-log phase $\left(\mathrm{OD}_{600}=0.40 ;\right.$ Spectronic 20D spectrophotometer $)$. Cultures were centrifuged $(3500 \times g$ for $7 \mathrm{~min})$, washed once in PBS, re-centrifuged, then resuspended in an equal volume of PBS. Bacterial suspensions were diluted in PBS to achieve desired injection doses in a $100 \mu$ injection volume (Table 1).

HSB. Juvenile HSB (Morone chrysops $\times$ M. saxatilis; Keo Fish Farms, Keo, AR) were held in recirculating $1000 \mathrm{ltanks}$ at $20 \pm 2^{\circ} \mathrm{C}$ prior to use in vaccine challenges. All fish were fed daily with $3.5 \mathrm{~mm}$ highprotein $(40 \%)$ sinking pellet feed (Nelson's Silver Cup Trout Feed) and were maintained on a $12 \mathrm{~h}$ light:12 h dark cycle.

I.p. vaccination. Each Streptococcus iniae strain was serially diluted in PBS and plated on THA to confirm the dose injected. The formalin-killed bacterin was also delivered in a $100 \mu$ l volume $\left(\sim 3 \times 10^{8} \mathrm{CFU} \mathrm{fish}^{-1}\right)$. Mock vaccinate groups included fish injected with PBS only and a group injected with adjuvant plus THB (100 $\mu$ l volumes). Groups of 25 juvenile HSB ( 15 g) were anesthetized with MS-222 (25 mg l-1; Western Chemical), weighed, and fin-clipped (right or left caudal, pectoral, or pelvic) for identification by treatment group. Bacteria were delivered i.p. using a $1.0 \mathrm{ml}$ syringe and 27-gauge needle. Initially, vaccinate groups were held separately in $100 \mathrm{l}$ tanks at $26 \pm 1^{\circ} \mathrm{C}$ with flow-through water and aeration for 2 wk. Fish were fed sparingly and monitored daily for survival. Brain cultures were taken from mortalities via brain swab following preparation as previously described (Phelps et al. 2009) to identify the possibility of infection from the vaccine strain. Swabs were streaked on THA and screened by PCR to positively identify vaccine strains. After the $2 \mathrm{wk}$ holding period, vaccinated fish were transferred into $1000 \mathrm{l}$ recirculating tanks and cohabitated. Fish were held for an additional $3 \mathrm{wk}$ ( $\sim 800$ degree-days total) at $20 \pm 1^{\circ} \mathrm{C}$ and fed to satiation daily. Two days prior to WT challenge, 3 fish were randomly sampled from each group for analysis of $S$. iniae-specific serum immunoglobulin M (IgM) levels; however, high assay background variation prevented conclusive analysis of immunoglobulin response trends.

Immersion vaccination. A 1.01 culture of each Streptococcus iniae strain (mid-log phase, cultured as described for live i.p. vaccines) was added to 9.01 of dechlorinated system water in an aerated 5.0 gallon (19 1) plastic bucket $\left(\sim 3.0 \times 10^{7} \mathrm{CFU} \mathrm{m}^{-1}\right.$ final concentration) (Table 1). The K288 bacterin was diluted 1:80 in system water $\left(\sim 4 \times 10^{7} \mathrm{CFU} \mathrm{ml}^{-1}\right)$ for HSB immersion vaccinations. A $10 \%$ THB solution served as a mock immersion vaccination control. Fish $(\mathrm{n}=25$ treatment group $^{-1}$ ) were anesthetized, fin-clipped, and weighed prior to immersion in their respective solutions for a period of $90 \mathrm{~min}$. All immersion vaccinations were performed in 10.01 volumes. Immersion vaccinated fish were maintained and fin-clipped as described for the i.p. vaccinate groups.

WT Streptococcus iniae challenge. After 800 degreedays, vaccinates were removed from the holding tanks and sorted into $100 \mathrm{l}$ flow-through challenge tanks. Over $2 \mathrm{~d}$, tanks were heated up from $20^{\circ} \mathrm{C}$ to the challenge temperature of $26^{\circ} \mathrm{C}$. Fish were anesthetized and challenged i.p. with $1 \times 10^{6} \mathrm{CFU}$ (in $100 \mu \mathrm{l}$ ) of WT K288 (preparation as described for live vaccines), then fed lightly and monitored for survival for $2 \mathrm{wk}$ post challenge. Bacteria recovered from all mortalities were confirmed to be WT $S$. iniae through culture and PCR analysis. Vaccine trials were conducted in a facility certified by the Association and Accreditation of Laboratory Animal Care (AAALAC International) following protocols approved by the Institutional Animal Care and Use Committee (IACUC).

Statistical analysis. Survival data were analyzed using a log-rank test included in the GraphPad Prism software suite (GraphPad Software). A p-value < 0.05 was considered statistically significant. Relative percent survival (RPS) was calculated by the following equation: $\{1$ - [(vaccinate mortality)/(control mortality)]\} $\times 100$ (Amend 1981). 


\section{RESULTS}

\section{Survival post-vaccination}

Both i.p. and bath-immersion vaccination of HSB using the 3 attenuated Streptococcus iniae mutants and the killed bacterin were generally well tolerated by the fish (Table 2). As expected, no post-vaccination mortalities occurred in any of the mock vaccination control groups or in the killed bacterin group. Consistent with previous HSB i.p. virulence studies for the $\Delta p g m A$ (Buchanan et al. 2005) and $\Delta c p s D$ (Locke et al. 2007a) mutants, i.p. vaccination with $10^{7} \mathrm{CFU}$ of each of these strains generated no mortalities. These 2 mutants were also avirulent when delivered through bath immersion. The $\Delta \operatorname{sim} A$ mutant was the only vaccine candidate to generate vaccination-related mortalities in both groups (16\% with i.p., $12 \%$ with immersion). S. iniae recovered from the brains of dead fish from the $\Delta \operatorname{sim} A$ mutant group were positively identified as the mutant strain through PCR analysis.

\section{Survival post-WT challenge}

Fish were held for 5 wk post-vaccination (800 degree-days), a sufficient holding period to ensure that any protection against WT

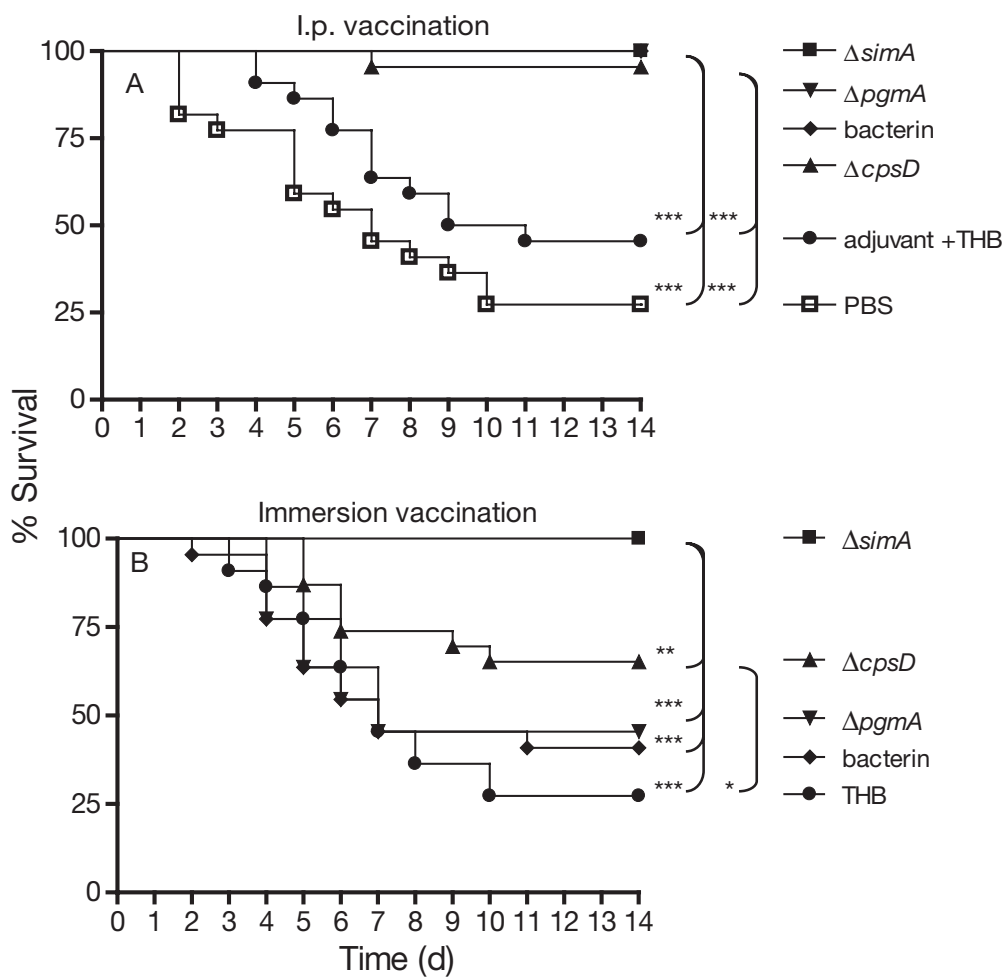

Fig. 1. Survival of hybrid striped bass (HSB; Morone chrysops $\times$ M. saxatilis) vaccinated against Streptococcus iniae. HSB vaccinated through (A) intraperitoneal (i.p.) injection or (B) bath immersion were challenged with a lethal dose of wild-type (WT) S. iniae after an 800 degree-day holding period. Kaplan-Meier plots show survival over a $14 \mathrm{~d}$ monitoring period post-challenge. Significant differences between survival data sets: ${ }^{*} p<0.05,{ }^{* *} p<0.01,{ }^{* * *} p<0.001$. PBS $=$ phosphate-buffered saline, THB = Todd-Hewitt broth. See Table 1 for description of $S$. iniae mutants $\Delta \operatorname{sim} A, \Delta c p s D$, and $\Delta p g m A$
Table 2. Summary of Streptococcus iniae vaccine trial data. i.p. = intraperitoneal, na = not applicable, $\mathrm{PBS}=$ phosphatebuffered saline, THB = Todd-Hewitt broth, WT = wild-type See Table 1 for description of $S$. iniae mutants $\Delta \operatorname{sim} A, \Delta c p s D$, and $\triangle p g m A$

\begin{tabular}{|c|c|c|c|}
\hline $\begin{array}{l}\text { Vaccination } \\
\text { group }\end{array}$ & $\begin{array}{c}\text { Vaccination } \\
\text { survival (\%) }\end{array}$ & $\begin{array}{l}\text { WT challenge } \\
\text { survival }(\%)\end{array}$ & $\begin{array}{c}\text { Relative \% } \\
\text { survival }\end{array}$ \\
\hline \multicolumn{4}{|l|}{ I.p. injection } \\
\hline$\Delta \operatorname{sim} A$ & 84 & 100 & 100 \\
\hline$\Delta c p s D$ & 100 & 96 & 95 \\
\hline$\Delta p g m A$ & 100 & 100 & 100 \\
\hline PBS control & 100 & 27 & na \\
\hline K288 bacterin & 100 & 100 & 100 \\
\hline $\begin{array}{l}\text { Adjuvant }+ \\
\text { THB control }\end{array}$ & 100 & 46 & 26 \\
\hline \multicolumn{4}{|l|}{ Bath immersion } \\
\hline$\Delta \operatorname{sim} A$ & 88 & 100 & 100 \\
\hline$\Delta c p s D$ & 100 & 64 & 51 \\
\hline$\Delta p g m A$ & 100 & 46 & 26 \\
\hline K288 bacterin & 100 & 41 & 19 \\
\hline THB control & 100 & 27 & na \\
\hline
\end{tabular}

Streptococcus iniae challenge (Fig. 1) was a result of adaptive immunity rather than prolonged upregulation of the innate immune system. Following i.p. challenge of all vaccinated fish with $1 \times 10^{6} \mathrm{CFU}$ of WT $S$. iniae, $27 \%$ survival was seen in the THB and PBS mock vaccination groups (Table 2). The THB plus adjuvant i.p. control group had slightly increased survival (46\%) compared to the corresponding PBS control group, perhaps through nonspecific immune stimulation, though the 2 survival curves were not significantly different $(p=0.13)$. No mortalities were observed in fish that had been vaccinated i.p. with $\Delta \operatorname{sim} A, \Delta p g m A$, or the killed bacterin. One fish died ( $96 \%$ survival) in the $\Delta c p s D$ i.p. vaccinate group following WT challenge. With the exception of the $\Delta \operatorname{sim} A$ vaccinate group $(100 \%$ survival), where no mortalities were seen, immersion vaccination groups suffered lower post-challenge survival levels than they did following injection vaccination: $64 \%$ for $\Delta c p s D, 46 \%$ for $\Delta p g m A$, and $41 \%$ for bacterin. 


\section{Overall vaccine efficacy}

The adaptive immuno-protection conferred by each vaccine was assessed through calculation of RPS. For i.p. vaccination, the $\Delta p g m A$ and killed bacterin i.p. vaccine groups had perfect protection profiles $(100 \%$ RPS) during the trial (Table 2). However, for immersion vaccination, the $\Delta p g m A$ and bacterin vaccines were the worst overall immersion candidates, with RPS values of 26 and $19 \%$, respectively; the groups were not significantly different from the survival of the THB immersion control group $(\mathrm{p}=0.51$ and $\mathrm{p}=0.66$, respectively). The ${ }_{c} c p s D$ mutant had $95 \%$ RPS through i.p. delivery, a value not significantly different from the $\Delta p g m A$ and bacterin groups $(\mathrm{p}=0.37)$. The $\Delta c p s D$ immersion-vaccinated group had an RPS value of $51 \%$ and was significantly more protective $(\mathrm{p}=0.01)$ than the THB immersion control group. The $\Delta \operatorname{sim} A$ mutant was the only vaccine to achieve $100 \%$ RPS in all surviving fish through both delivery methods.

\section{DISCUSSION}

As knowledge of Streptococcus iniae virulence increases and a growing number of virulence factor-deficient mutants are available, the vaccine potential of the most attenuated of these mutants can be assessed. We evaluated 3 such $S$. iniae mutants lacking capsular polysaccharide $(\Delta c p s D)$, M-like protein $(\Delta \operatorname{sim} A)$, and phosphoglucomutase $(\Delta p g m A)$. The efficacy of each live mutant was compared through i.p. injection and bath immersion in parallel with an isogenic, adjuvanted, formalin-killed bacterin. Both live and killed vaccine candidates generated 95 to $100 \%$ RPS values when delivered by injection. However, through immersion delivery, only the $\Delta \operatorname{sim} A$ live mutant provided a high level of protection (100\% RPS), demonstrating for the first time the superior efficacy of live $S$. iniae vaccines in this commercially desirable delivery method. The present study also highlights some of the challenges faced with live vaccines, such as vaccination safety and the balance between attenuation, efficacy, and the conservation of immunodominant epitopes.

Despite its high protective capacity in both delivery models, the $\Delta \operatorname{sim} A$ mutant was the only 1 of the 3 live strains tested that lacked complete attenuation at the delivered dose. The $16 \%$ mortality observed after i.p. vaccination in the present study is greater than the $8 \%$ mortality observed at a similar dose in previous work with this mutant (Locke et al. 2008), potentially attributable to the higher temperature at vaccination employed here compared to previous work (26 vs. $24^{\circ} \mathrm{C}$ ), although these differences may not be biologically significant. Increase in temperature correlates positively with Streptococcus iniae virulence (Kitao 1993), and the use of outbred fish may also account for some of the variability in HSB susceptibility to $S$. iniae infection. Regardless, in order to minimize prevaccination mortalities, the $\Delta \operatorname{sim} A$ mutant will require further mutagenesis-based attenuation or optimization of vaccination conditions, for example by lowering the immunization dose or using cooler water temperature.

Past research has indicated that the $\Delta \operatorname{sim} A$ mutant has a reduced ability to invade and adhere to epithelial cells (Locke et al. 2008). Because the $\Delta \operatorname{sim} A$ mutant retained sufficient abilities for host interaction to function in immersion vaccination, it suggests that the role of SiM in adherence and invasion of epithelial cells (Locke et al. 2008) may be shared or redundant with other Streptococcus iniae surface factors. The $\Delta \operatorname{sim} A$ mutant was able to provide complete immune protection against WT challenge and we speculate that the SiM protein itself is not an essential antigenic epitope involved in the adaptive immune response to $S$. iniae.

Properties of an ideal live vaccine include sufficient attenuation, low cytotoxicity, complete immune clearance, conservation of key antigenic epitopes, and stimulation of long-term adaptive immune protection. Studies of the $\Delta p g m A$ mutant, through the present study and earlier work using an extended 2000 degree-day trial (Buchanan et al. 2005), show that so far this mutant appears to meet all of these key criteria when delivered through injection. Despite a perfect i.p. safety and efficacy profile, the $\Delta p g m A$ mutant was a poor immersion vaccine candidate. Mutagenesis of pgm appears to have significantly reduced the ability of the bacteria to utilize natural water-based transmission routes, or perhaps weakening of the cell wall (Buchanan et al. 2005) has lowered the ability of this mutant to handle osmotic stress and therefore has diminished viability in water-based immersion delivery.

The adjuvanted, formalin-killed bacterin used in the present study was prepared according to a commercial protocol used at an aquaculture facility that vaccinates fish using autogenous Streptococcus iniae isolates and thus serves as a relevant comparator vaccine. The bacterin, when injected at a log-greater CFU than the live attenuated vaccines, provided complete protection. Efficacy of the whole-cell bacterin may also be in part due to the inclusion of supernatant from the liquid culture in the injected bacterin. Previous work with whole-cell killed bacterins has demonstrated the importance of small extracellular products in the adaptive immune response (Klesius et al. 2000); live vaccines offer the advantage that they inherently produce these small immunogenic compounds in vivo and in their native form. Despite high levels of protection when delivered i.p., the killed bacterin performed 
poorly in the immersion trial and did not provide statistically significant protection against WT $S$. iniae. Development of localized immunity at the site of i.p. injection vaccination (followed by i.p. challenge) may have contributed slightly to the efficacy of injected vaccination over immersion vaccination. Nevertheless, the present results indicate a failure to induce significant protection by immersion.

While injection vaccination is precise and reproducible, it is also labor- and cost-intensive and is thus restricted in application to only higher-value aquaculture species such as salmonids and HSB. Immersion vaccination is more economical and more closely mimics natural infection routes utilized by aquatic pathogens, resulting in a potentially more robust immune response. I.p. vaccination with all candidate Streptococcus iniae vaccines provided $>95 \%$ RPS; however, immersion administration of these same vaccines failed to provide high levels of adaptive immune protection, with the exception of the $S$. iniae $\Delta \operatorname{sim} A$ mutant. Other studies have shown similar trends with superior protection of killed bacterins for closely related streptococcal species when delivered through injection versus immersion (Iida et al. 1982, Evans et al. 2004). The ability to effectively deliver a vaccine through immersion may be a key feature of live attenuated vaccines that cannot be replicated with killed alternatives and may make them more attractive to commercial users.

Successful passive vaccination experiments suggest that the immune response to Streptococcus iniae infection is largely antibody-mediated (Shelby et al. 2002, Evans et al. 2006). Kinetic studies of the specific IgM response of fish to vaccination with live $S$. iniae strains could be an interesting comparison to the response generated with killed bacterins. Another avenue of investigation with live vaccines should focus on assessing their cross-protective capabilities against $S$. iniae serotypes. Emergence of serologically distinct strains in operations where fish have been vaccinated is a problem with $S$. iniae vaccination efforts (Bachrach et al. 2001). Studies have shown that vaccination with a bacterin composed of multiple serotypes provides a superior protective advantage (Klesius et al. 2000), but just how much cross-protection is generated with live vaccines is unknown.

Live bacterial vaccines have demonstrated sufficient efficacy and safety for use in finfish aquaculture. Three live attenuated vaccines have already received approval by the United States Department of Agriculture (USDA) for use in US aquaculture: AQUAVAC-ESC ${ }^{\circledR}$ (Intervet/Schering-Plough Animal Health) for prevention of enteric septicemia in catfish caused by Edwardsiella ictaluri (Klesius \& Shoemaker 1999), AQUAVAC$\mathrm{COL}^{\mathrm{TM}}$ (Intervet/Schering-Plough Animal Health) for prevention of columnaris in catfish caused by Flavobacterium columnare (Shoemaker et al. 2007), and Renogen $^{\mathrm{TM}}$ (Novartis Animal Health) for prevention of infections in salmonids caused by Renibacterium salmoninarum and Piscirickettsia salmonis using an Anthrobacter davidanieli strain (Salonius et al. 2005). These successes demonstrate the potential of live attenuated vaccines for aquaculture application. Two issues would need to be considered prior to application of a live attenuated Streptococcus iniae vaccine. First, the vaccine strain would need to be incapable of reversion back to $\mathrm{WT}_{\text {; }}$ this is true of the allelic exchange mutants used in the present study where the virulence gene has been deleted. The other main criterion would be the absence of any antibiotic resistance genes; these are found in the allelic exchange mutants used in the present study, but they could easily be removed via subsequent targeted deletion mutagenesis.

In sum, we have evaluated a panel of 3 attenuated live Streptococcus iniae vaccine candidates and an adjuvanted WT bacterin using injection and immersion delivery. While high levels of protection were achieved with all vaccines delivered through i.p. injection, the $\Delta \operatorname{sim} A$ mutant was the only vaccine to provide complete protection when delivered via immersion delivery. This finding highlights a potential advantage of invasive live attenuated vaccines over killed-bacterin alternatives in an immersion application. Future largescale studies should investigate the long-term efficacy and multi-strain cross-protective capacity of these promising live vaccine candidates. Oral delivery of the live attenuated vaccines should also be tested with these vaccine strains, as this commercially desirable method of vaccination, like immersion delivery, utilizes a known route of infection in $S$. iniae (Perera et al. 1997, Bromage \& Owens 2002) and may be well suited for use with live attenuated mutants.

Acknowledgements. This publication was supported in part by the National Sea Grant College Program of the US Department of Commerce's National Oceanic and Atmospheric Administration (NOAA) under NOAA grant \#NA04OAR4170038, project \#59-A-N, through the California Sea Grant College Program; and in part by the California State Resources Agency. The views expressed herein do not necessarily reflect the views of any of those organizations. Additional funding was provided by the NIH Training Program in Marine Biotechnology grant \#5 T32 GM067550. We thank Kent SeaTech Corporation for providing the use of fish and challenge facilities. Finally, we thank MVP Laboratories for providing the EMULSIGEN ${ }^{\circledR}$ adjuvant.

\section{LITERATURE CITED}

Agnew W, Barnes AC (2007) Streptococcus iniae: an aquatic pathogen of global veterinary significance and a challenging candidate for reliable vaccination. Vet Microbiol 122: $1-15$ 
Amend DF (1981) Potency testing of fish vaccines. In: Hennessen W, Anderson DP (eds) Developments in biological standardization, Vol 49. Karger, Basel, p 447-454

Bachrach G, Zlotkin A, Hurvitz A, Evans DL, Eldar A (2001) Recovery of Streptococcus iniae from diseased fish previously vaccinated with a streptococcus vaccine. Appl Environ Microbiol 67:3756-3758

Baiano JC, Tumbol RA, Umapathy A, Barnes AC (2008) Identification and molecular characterisation of a fibrinogen binding protein from Streptococcus iniae. BMC Microbiol 8:67

Bromage ES, Owens L (2002) Infection of barramundi Lates calcarifer with Streptococcus iniae: effects of different routes of exposure. Dis Aquat Org 52:199-205

Buchanan JT, Stannard JA, Lauth X, Ostland VE, Powell HC, Westerman ME, Nizet V (2005) Streptococcus iniae phosphoglucomutase is a virulence factor and a target for vaccine development. Infect Immun 73:6935-6944

Eldar A, Bejerano Y, Livoff A, Horovitcz A, Bercovier H (1995) Experimental streptococcal meningo-encephalitis in cultured fish. Vet Microbiol 43:33-40

Eldar A, Horovitcz A, Bercovier H (1997) Development and efficacy of a vaccine against Streptococcus iniae infection in farmed rainbow trout. Vet Immunol Immunopathol 56: 175-183

Evans JJ, Klesius PH, Shoemaker CA (2004) Efficacy of Streptococcus agalactiae (group B) vaccine in tilapia (Oreochromis niloticus) by intraperitoneal and bath immersion administration. Vaccine 22:3769-3773

Evans JJ, Klesius PH, Shoemaker CA (2006) Therapeutic and prophylactic immunization against Streptococcus iniae infection in hybrid striped bass (Morone chrysops $\times$ Morone saxatilis). Aquacult Res 37:742-750

Fuller JD, Camus AC, Duncan CL, Nizet V and others (2002) Identification of a streptolysin S-associated gene cluster and its role in the pathogenesis of Streptococcus iniae disease. Infect Immun 70:5730-5739

Iida T, Wakabayashi H, Egusa S (1982) Vaccination of control of streptococcal disease in yellowtail. Fish Pathol 16: 201-206

Kitao T (1993) Streptococcal infections. In: Inglis V, Roberts RJ, Bromage NR (eds) Bacterial diseases of fish. Blackwell Scientific Publications, Oxford, p 196-210

Klesius PH, Shoemaker CA (1999) Development and use of modified live Edwardsiella ictaluri vaccine against enteric septicemia of catfish. Adv Vet Med 41:523-537246

Klesius PH, Shoemaker CA, Evans JJ (2000) Efficacy of single and combined Streptococcus iniae isolate vaccine administered by intraperitoneal and intramuscular routes in tilapia (Oreochromis niloticus). Aquaculture 188:237-246

Locke JB, Colvin KM, Datta AK, Patel SK and others (2007a) Streptococcus iniae capsule impairs phagocytic clearance and contributes to virulence in fish. J Bacteriol 189: 1279-1287

Locke JB, Colvin KM, Varki N, Vicknair MR, Nizet V,

Editorial responsibility: David Bruno,

Aberdeen, UK
Buchanan JT (2007b) Streptococcus iniae $\beta$-hemolysin streptolysin $\mathrm{S}$ is a virulence factor in fish infection. Dis Aquat Org 76:17-26

Locke JB, Aziz RK, Vicknair MR, Nizet V, Buchanan JT (2008) Streptococcus iniae M-like protein contributes to virulence in fish and is a target for live attenuated vaccine development. PLoS ONE 3:e2824

Lowe BA, Miller JD, Neely MN (2007) Analysis of the polysaccharide capsule of the systemic pathogen Streptococcus iniae and its implications in virulence. Infect Immun 75: 1255-1264

Marsden MJ, Vaughan LM, Foster TJ, Secombes CJ (1996) A live (delta aroA) Aeromonas salmonicida vaccine for furunculosis preferentially stimulates T-cell responses relative to B-cell responses in rainbow trout (Oncorhynchus mykiss). Infect Immun 64:3863-3869

Marsden MJ, Vaughan LM, Fitzpatrick RM, Foster TJ, Secombes CJ (1998) Potency testing of a live, genetically attenuated vaccine for salmonids. Vaccine 16:1087-1094

Perera RP, Johnson SK, Lewis DH (1997) Epizootiological aspects of Streptococcus iniae affecting tilapia in Texas. Aquaculture 152:25-33

> Phelps HA, Runft DL, Neely MN (2009) Adult zebrafish model of streptococcal infection. Curr Protoc Microbiol Chapter 9:Unit 9D 1

Pier GB, Madin SH (1976) Streptococcus iniae sp.nov., a betahemolytic streptococcus isolated from an Amazon freshwater dolphin, Inia geoffrensis. Int J Syst Bacteriol 26: $545-553$

Salonius K, Siderakis C, MacKinnon AM, Griffiths SG (2005) Use of Arthrobacter davidanieli as a live vaccine against Renibacterium salmoninarum and Piscirickettsia salmonis in salmonids. Dev Biol (Basel) 121:189-197

Shelby RA, Klesius PH, Shoemaker CA, Evans JJ (2002) Passive immunization of tilapia, Oreochromis niloticus (L.), with anti-Streptococcus iniae whole sera. J Fish Dis 25:1-6

Shoemaker CA, Klesius PH, Evans JJ (2001) Prevalence of Streptococcus iniae in tilapia, hybrid striped bass, and channel catfish on commercial fish farms in the United States. Am J Vet Res 62:174-177

Shoemaker CA, Klesius PH, Evans JJ (2007) Immunization of eyed channel catfish, Ictalurus punctatus, eggs with monovalent Flavobacterium columnare vaccine and bivalent F. columnare and Edwardsiella ictaluri vaccine. Vaccine 25:1126-1131

> Shutou K, Kanai K, Yoshikoshi K (2007) Virulence attenuation of capsular polysaccharide-deleted mutants of Streptococcus iniae in Japanese flounder Paralichthys olivaceus. Fish Pathol 42:41-48

Sommerset I, Krossy B, Biering E, Frost P (2005) Vaccines for fish in aquaculture. Expert Rev Vaccines 4:89-101

> Zlotkin A, Chilmonczyk S, Eyngor M, Hurvitz A, Ghittino C, Eldar A (2003) Trojan horse effect: phagocyte-mediated Streptococcus iniae infection of fish. Infect Immun 71 : 2318-2325

Submitted: July 30, 2009; Accepted: December 15, 2009

Proofs received from author(s): February 23, 2010 